\title{
Perancangan Buku Ilustrasi Anxiety Disorder sebagai Media Edukasi BagiUsia 19-24 Tahun
}

\author{
Ardika Priyata $^{1 *}$, Heru Dwi Waluyanto ${ }^{2}$, Aznar Zacky $^{3}$ \\ 1,2 Program Studi Desain Komunikasi Visual, Fakultas Seni dan Desain \\ Universitas Kristen Petra, Jl. Siwalankerto No.121-131, Surabaya \\ ${ }^{3}$ Program Studi Desain Komunikasi Visual, Fakultas Seni Rupa, \\ Institut Seni Indonesia Yogyakarta, Jl. Parangtritis Km. 6.5, Yogyakarta \\ *Penulis korespondensi; E-mail: ardikapriyata@gmail.com
}

\begin{abstract}
Abstrak
Masalah anxiety disorder banyak mendapat stigma buruk dari masyarakat karena dikaitkan dengan kegilaan. Media untuk mempelajari anxiety disorder ini masih kurang diminati oleh masyarakat, mengakibatkan kurangnya wawasan masyarakat tentang masalah ini. Bentuk buku tebal dan padat membuat kesan intimidatif bagi orang yang ingin membacanya. Maka dari itu situasi ini memerlukan media yang dapat menarik minat oranguntuk membacanya. Maka dari itu media yang dipilih adalah buku ilustrasi. Ilustrasi di sini akan dijadikan sebagai cara untuk menampilkan konsep anxiety disorder dalam wujud visual. Konsep tentang macam-macam tipe anxiety disorder akan dijelaskan melalui narasi karakter. Target audiens merupakan masyarakat berusia 19- 24 tahun. Dengan adanya media ini diharapkan dapat menarik minat, menambah wawasan, serta mengubah persepsi yang mengaitkan anxiety disorder dengan kegilaan dan pengasingan.
\end{abstract}

Kata kunci: anxiety disorder, media edukasi, ilustrasi, 19-24 tahun.

\begin{abstract}
Anxiety disorder as a problem comes with a lot of bad stigma from the community as it is associated with madness. The media to learn about anxiety disorder is still lacking in public interest, resulting in a lack of publicawareness about this problem. A thick and solid book gives an intimidating impression for people who want to read it. Therefore this situation requires media that can attract people to read. That is why the chosen media is an illustration book. The illustrations here will be used as a way to display the concept of anxiety disorder in visual form. The concept of various types of anxiety disorder will be explained through character narratives. Thetarget audiens is people aged 19-24 years. This media is expected to be able to attract interest, add insight, and change the perception that associates anxiety disorder with insanity and isolation.
\end{abstract}

Keywords: anxiety disorder, education media, illustration, people aged 19-24 years.

\section{Pendahuluan}

Pada dasarnya manusia memiliki aspek fisik dan kejiwaan/mental yang mendukung kehidupannya secara individu. Aspek kesehatan fisik adalah aspek yang terlihat karena berkaitan dengan kondisi fisik. Berbeda dengan aspek kesehatan mental, aspek inimerupakan hal yang sedikit sulit untuk diamati secara langsung karena menyangkut dengan keadaan mental diri pribadi seorang individu.

Aspek mental ini tidak kalah penting bila dikaitkan dengan kehidupan seorang individu. Kondisi kestabilan kesehatan antara mental dan fisik adalah hal yang saling mem- pengaruhi. Dalam buku Emotional Intellegence dikatakan bahwa orang yang berpandangan cerah, tentu saja lebih mampu bertahan menghadapi keadaan sulit, termasuk kesulitan medis." (Goleman, 1995)

Salah satu gejala aspek mental yang sering dialami adalah stres. Menurut buku Psychology Themes and Variation yang ditulis oleh Wayne Weiten, stres adalah keadaan yang mengancam atau dianggap mengancam kesejahteraan seseorang dan dengan demikian membebani kemampuan seseorang untuk mengatasi sesuatu. Ancaman tersebut biasanyamengarah pada keamanan fisik, kemanan jarak jauh, kepercayaan diri, reputasi, kete- 
nangan pikiran, danmasih banyak lagi selagi dianggap penting oleh seorang individu.

Efek yang ditimbulkan dari stres bisa mempengaruhi emosi, pola pikir, dan juga perilaku dari orang yang merasakannya. Menurut Beilock (2010), orang yang umumnya bekerja dalam keadaan under-pressure biasanya tingkat perhatian dan kualitas kerjanya akan menurun akibat kekhawatiran tentang performa yang dilakukan. Selain itu stres seringkali menjadi faktor pemicu gangguan psikologis seperti Anxiety Disorder (gangguan kecemasan), depresi, hingga munculnya keinginan untuk bunuh diri.

Menurut Kate Strong, seorang ahli epidemiologi WHO, bunuh diri akibat depresi merupakan penyebabkematian remaja terbesar ke-3 di dunia. Data WHO menunjukkan pada tahun 2015 ada 67 ribu remaja yang meninggal akibat bunuh diri. Hal ini disebabkan karena usia remaja rawan mengalami anxiety disorder. Angka bunuh diri tertinggi terdapat di Eropa dan Asia Tenggara.

Salah satu contoh kasus bunuh diri adalah meninggalnya artis peran sekaligus penyanyi asal Korea, Choi Jin-ri atau yang dikenal dengan Sulli. Mendiang ditemukan meninggal dunia akibat gantungdiri di lantai 2 rumahnya di Seongnam, Seol, pada hari Senin 14 Oktober 2019. Dikabarkan pada tahun 2014 Sulli pernah mendapatkan perawatan kesehatan mental karena mengidap Panic Disorder yang merupakan bagian dari Anxiety Disorder (Kompas, 2019), sedangkan di Indonesia sendiri, kasus bunuh diri akibat depresi mulai mengancam kalangan pelajar. Ketua Perhimpunan Dokter Spesialis Kedokteran JiwaDKI Jakarta mengungkapkan, merujuk pada penelitian yang dibuatnya, 5\% pelajar dari 910 pelajar SMAN dan SMKN akreditasi A di DKI Jakarta memiliki ide bunuh diri.

Stigma buruk dari masyarakat umum menganggap penderita anxiety disorder sebagai individu yang aneh. Untuk itu penderita layak diasingkan oleh masyarakat. Hal ini sangat mengecewakan karena dapat mengurangi kemungkinan untuk seorang penderita anxiety disorder pulih (BBC News Indonesia, 2019).

Akibatnya para penderita anxiety disorder malah banyak yang memilih diam agar stigma buruk itu tidak menimpa mereka. Hal ini akan semakin menyulitkan masyarakat untuk melihat gejala-gejala gangguan mental tersebut.
Pada akhirnya mengakibatkan anxiety disorder menjadi sebuah penyakit yang sulit diantisipasi.

Tanpa adanya penanganan yang baik, angka penderita gangguan jiwa di Indonesia akan terus bertambah. Untuk itu pemberian informasi, mengedukasi masyarakat sangatlah penting terkait kesehatan mental agar stigma yang ada di masyarakat dapat dihilangkan dan penderita mendapatkan penanganan yang tepat.

Perancangan yang diangkat sebagai solusi atas kurangnya informasi dan edukasi tentang gangguan psikologis, khususnya anxiety disorder, adalah buku ilustrasi. Buku ini akan memvisualkan tentang anxiety disorder, karena dengan memberikan wujud visual dapat menimbulkan persepsi bahwa anxiety disorder merupakan hal yang dapat diatasi. Dengan demikian stigma buruk beserta anggapan bahwa anxiety disorder tidak dapat disembuhkan diharapkan akanberangsur-angsur hilang.

Pendekatan ilustrasi digunakan karena aspek mental merupakan hal yang sulit untuk diamati secara kasat mata. Ilustrasi yang ditampilkan berfungsi untuk menerjemahkan apa yang dirasakan oleh penderita anxiety disorder sehingga gambaran yang akandihasilkan bersifat imajinatif yang akan lebih menarik bila menggunakan ilustrasi. Namun penggunaan ilustrasi tidak lepas dari tujuan agar pembaca dapat memahami pesan yang disampaikan oleh penulis secara jelas.

Selain itu, ilustrasi dapat memengaruhi persepsi seseorang melalui faktor visual. Persepsi seseorang terhadap suatu hal dapat dipengaruhi oleh pemilihan indera yang digunakan, sehingga ilustrasi bisa dijadikan sebagai motivasi pembaca untuk lebihmenyimak isi dari buku ini melalui faktor visual (Weiten, 2013).

Target audiens dari perancangan ini adalah masyarakat dengan rentang usia 19-24 tahun. Menurut John Amos Comenius, dalam usia tersebut seseorang akrab berada di tahap perkembangan fungsi kemampuan berdikari, self direction, dan self control. Seorang mulai mengalami proses pembudayaan dengan menghayati nilai-nilai ilmiah, disamping mempelajari macam-macam ilmu pengetahuan. Menurut psikolog Rena Masri, usia remaja akhir merupakan usia dimana seorang individu mulai mendapat tekanan dalam hal perkuliahan, pekerjaan, pernikahan, dan lain-lain 
sehingga dalam usia ini seorang akan mulai rentan untuk terkena depresi. Secara psikologis dan behavioristik, target audiens merupakan orang yang senang mempelajari hal baru, mengikuti tren, dan menyukai hal-hal yang berkaitan dengan dunia seni khususnya ilustrasi. Target audiens juga memiliki kegemaran membaca untuk menambah wawasan mereka.

Perancangan ini didukung oleh beberapa perancangan lainnya sebagai referensi. Salah satunya adalah perancangan berjudul "Perancangan Film Pendek Untuk Meningkatkan Kesadaran Depresi Bagi Mahasiswa" yang dirancang oleh Niko Tandra dari Program Studi DKV Universitas Kristen Petra tahun 2018 yang memberi gambaran akan cara mendukung orang terdekat yang sedang menderita gangguan depresi. Selain itu ada pula perancangan berjudul "Perancangan Film Pendek Untuk Meningkatkan Pemahaman Masyarakat Tentang Kleptomania" oleh Leonardus Dewabrata dari Program Studi DKV Universitas Kristen Petra tahun 2018, yang membahas tentang gangguan psikologis Kleptomania melalui media film pendek.

Ada pula perancangan berjudul "Perancangan Webtoon Mengenai Pengenalan Gangguan Pemusatan Perhatian pada Mahasiswa" oleh Monica Marvel dari Program Studi DKV Universitas Kristen Petra tahun 2018, yang membahas permasalahan tentang $A D H D$ dengan menggunakan komik webtoon sebagai medianya. Jika dibandingkan dengan ketiga perancangan tersebut, maka kebaruan yang dimiliki oleh perancangan ini adalah pada bagian topik yang membahas tentang anxiety disorder dengan menggunakan buku ilustrasi sebagai media edukasi.

Berdasarkan data di atas, maka dapat disimpulkan bahwa perancangan buku ilustrasi anxiety disorder sebagai media edukasi perlu dilakukan. Target audiens yang diambil adalah remaja berusia 18-24 tahun. Harapannya supaya stigma buruk tentang penyakit psikologis ini dapat berangsur-angsur hilang melalui buku ilustrasi anxiety disorder sebagai media edukasi.

\section{Metode}

Metode perancangan dengan memperoleh data terkait dengan kualitatif melalui wawancara dan studi pustaka. Selain itu juga ada data kuantitatif melalui kuesioner yang berfungsi sebagai pelengkap.

Data yang dikumpulkan untuk perancangan ini adalah teori-teori seputar anxiety disorder atau bidang-bidang sejenis. Data ini diperoleh dari artikel, situs online, jurnal, buku dan laporan yang ditulis oleh paraahli di bidang psikologis beserta tentang gangguannya. Selain itu data wawancara juga diperoleh dari hasil wawancara dengan psikolog dari Pusat Konseling \& Pengenmbangan Pribadi (PKPP) Universitas Kristen Petra.

Metode yang digunakan adalah 5W1H. Metode inidigunakan untuk mencari tahu pokok permasalahan terkait dengan apa yang dialami target audiens. Metode ini juga dapat membantu dalam menganalisis data dari literatur agar dapat sesuai dengan permasalahan sehingga pada akhirnya perancangan buku ilustrasi ini dapat menjawab permasalahan yang ada di lingkup target audiens.

\section{Pembahasan}

\section{Perkembangan dan Fungsi Ilustrasi dalam Kehidupan Sosial}

Ilustrasi telah menjadi sumber visualisasi ide dan pikiran manusia sepanjang waktu. Ilustrasi juga telah mempengaruhi masyarakat dalam hal keyakinan dan tren. Sejarah ilustrasi tidak pernah lepas oleh buku, sebab fungsi dari ilustrasi sendiri pada mulanya adalah untuk menjelaskan isi dari buku tersebut.

Sejak jaman prasejarah, perkembangan ilustrasi sudah dapat dilihat melalui lukisan gua. Kemudian ilustrasi terus berkembang dengan adanya manuskrip pada abad pertengahan hingga buku dan surat kabar pada abad 15-18. Sekitar tahun 1890-1920 ilustrasi mengalami jaman keemasannya akibat adanya mesin cetak. Media cetak merupakan media komunikasi utama pada masa itu, sedangkan pada masa perang ilustrasi berperan dalam pembuatan poster propaganda.

Hingga kini ilustrasi kedepannya akan berkembang dalam beragam bidang dan media. Munculnya bidang concept art dalam industri perfilman dan video game menambah ruang bagi para illustrator untuk selalu berkembang. Selain video game, ilustrasi juga merambah masuk pada board game, trading card game, dan juga computer card game. 


\section{Pengaruh Faktor Visual terhadap Persepsi}

Persepsi seseorang terhadap suatu hal dapat dipengruhi oleh pemilihan indera yang digunakan (Weiten, 2013), sehingga ilustrasi bisa dijadikan sebagai motivasi pembaca untuk lebih menyimak isi dari buku ini melalui faktor visual.

Kesesuaian dapat dicapai melalui input visual yang dihubungkan dengan apa yang dipersepsikan. Hal ini menjadi alasan utama mengapa manusia melihat dunia dengan cara yang berbeda. Persepsi berperan pada interpretasi yang dibentuk oleh input dari indra visual. Maka dari itu proses interpretasi tersebut dapat dipengaruhi dengan cara memanipulasi ekspektasi pembaca. Kesiapan secara perseptual melalui ekspektasi tersebut akan mempengaruhi bagaimana seseorang menginterpretasikan input melalui indra visual mereka (Weiten, 2013).

Dalam ilustrasi, faktor-faktor visual tersebut dapat dijabarkan menjadi warna dan bentuk. Kombinasi dari kedua hal ini dapat memengaruhi persepsi yang ditimbulkan. Selain itu gaya visual semi-realistis juga membantu memberi kesan bahwa anxiety disorder merupakan hal yang dapat diatasi.

\section{Media Edukasi}

Media edukasi merupakan sebuah perantara yang digunakan untuk menyampaikan pesan dari komunikator kepada receiver-nya, dimana pesan yang disampaikan bertujuan untuk menyampaikan informasi dan edukasi. Tujuan dari media edukasi ini sendiri adalah untuk menyampaikan pesan pendidikan secara efektif, sehingga dapat memaksimalkan proses pembelajaran.

\section{Anxiety Disorder}

Setiap orang pasti mengalami rasa cemas dalam kehidupan sehari-hari. Hal ini merupakan hal yangwajar dan merupakan sebuah reaksi umum manusia terhadap kesulitan dalam hidupnya. Namun bagi beberapa orang, kecemasan bisa saja menjadi hal yang serius. Orang-orang ini dapat mengalami kecemasan tingkat tinggi dan dengan frekuensi yang cukup sering, sehingga level kecemasan yang tinggi tersebut akan sangat mengganggu keberlangsungan hiduporang yang mengalaminya.

Fenomena ini dinamakan gangguan kecemasan (anxiety disorder). Anxiety disorder merupakan sebuah kelas gangguan psikologis yang ditandai dengan adanya rasa cemas dan ketakutan yang sangat tinggi (Weiten, 2013). Gejala ketakutan yang dialami biasanya diikuti dengan gejala fisik, seperti gemetar, penegangan otot, diare, sakit kepala, kehilangankesadaran, berkeringat, dan palpitasi jantung.

Penelitian menyatakan bahwa fenomena ini terbilang cukup umum. Gangguan ini bisa dialami $19 \%$ dari seluruh populasi dunia (Dew, Bromet, \& Switzer, 2000; Regier \& Burke, 2000 dalam Weiten, 2013). Anxiety disorder terbagi lagi menjadi lima tipe, dan satu orang memiliki kemungkinan untuk mengidaplebih dari satu tipe anxiety disorder (Merikagas \& Kalaydjian, 2009 dalam Weiten, 2013).

\section{Generalized Anxiety Disorder}

Generalized anxiety disorder atau gangguan kecemasan menyeluruh ditandai dengan adanya rasa cemas yang diikuti dengan rasa takut yang berlebihan, meskipun objek atau situasi tersebut tidak menimbulkan ancaman secara khusus terhadap pengidapnya. Orang dengan gangguan ini selalumerasa cemas atas kesalahan dari masa lalu, atau permasalahan yang ditakuti di masa depan.

\section{Phobic Disorder}

Di dalam phobic disorder atau gangguan fobia, seseorang memiliki ketakutan yang terfokus pada suatu objek atau situasi tertentu, yang dimana objek ataupun situasi tersebut tidak menimbulkan ancaman secara khusus terhadap pengidapnya (Weiten, 2013). Fobia ringan sering terjadi secara umum. Namun sebuah fobia dianggap serius ketika mulaimengganggu keseharian pengdiapnya.

Para pengidap fobia mengakui bahwa ketakutan yang mereka alami tidak masuk akal, namun mereka tetap tidak bisa mengatasi rasa takut itu ketika dihadapkan dengan objek atau situasi tersebut. Bahkan hanya dengan membayangkan objek atau situasi yang ditakuti bisa memicu ketakutan yang sangat besar bagi pengidap fobia (Thorpe \& Salkovskis, 1995 dalam Weiten,2013).

\section{Post Traumatic Stres Disorder (PTSD)}

PTSD merupakan gangguan psikis yang terjadi pada saaat proses pemulihan dari pengalaman atas kejadian yang bersifat traumatis dan tergolong berat. PTSDmulai digolongkan sebagai gangguan psikologis pada sekitar tahun 1970 
setelah perang Vietnam. Banyak tentara veteran yang trauma akibat kejadian di saat pertempuran itu terjadi.

Namun PTSD sendiri tidak hanya menyerang para tentara yang terlibat perang. PTSD bisa menyerang seseorang yang pernah mengalami kejadian yang cukup traumatis seperti pemerkosaan atau penyerangan, kecelakaan fatal, bencana alam, atau menyaksikan kematian orang lain. Riset menunjukkanbahwa ada 7\% populasi manusia yang pernah mengalami PTSD dalam masa hidupnya (Resick, Monson, \& Rizvi, 2008 dalam Weiten, 2013).

Gejala umum yang dirasakan pengidap PTSD adalah merekonstruksi peristiwa traumatis tersebut dalam wujud mimpi buruk atau flashback, kelumpuhan emosional, pengasingan diri, masalah dalamhubungan social, ketakutan, amarah yang berlebihan, dan rasa bersalah yang berlebihan (McClure-Tone \& Pine, 2009). Bahkan individu dapat mengalami dissociative experience, yaitu sebuah pengalaman dimana sebuah peristiwa terasa tidak nyata danseolah-olah terlepas dari kenyataan.

\section{Obsessvie Compulsive Disorder (OCD)}

OCD ditandai dengan adanya intrusi kecemasan yang tidak diinginkan secara tidak terkontrol (obsesi), dan adanya tindakan kompulsif untuk menghilangkan kecemasan tersebut. Obsesi seringkali menjadi sebuah inti dari tindakan atau keinginan untuk melukai seseorang, kegagalan personal, bunuh diri, atau tindakan seksual. Orang yang memiliki obsesi seringkali kehilangan kendali atas pikiran mereka. Kompulsi berperan sebagai ritual untuk menghilangkan kecemasan sesaat.

Sebuah obsesi biasanya terkait dengan tindakan kompulsi untuk menangani obsesi tersebut. Contohnya bila obsesi terkait kontaminasi biasanya diatasi dengan tidakan kompulsif seputar kebersihan, obsesi tentang simetri dikaitkan dengan tindakan kompulsif seputar kerapian dan penyusunan (Hollander \& Simeon, 2008 dalam Weiten, 2013).

\section{Panic Disorder dan Agoraphobia}

Panic Disorder ditandai dengan adanya ketakutan berlebihan yang menyerang secara tiba-tiba disaat yang tidak terduga (Weiten, 2013). Kejadian ini diikuti dengan gejala fisik seperti gemetaran dan berkeringat diikuti dengan kondisi panik. Setelah beberapa serangan panik, pengidap akan mulai cemas, menganggap bila pengidap akan panik di depan umum. Hingga pada akhirnya pengidap memiliki kecenderungan untuk tidak keluar rumah akibat takut panik di depan umum. Kondisi ini nantinya dapat memicu agoraphobia.

Agoraphobia merupakan sebuah ketakutan untukkeluar ke tempat umum atau keramaian. Karena rasa takut ini, beberapa orang akan mengurung diri di rumah masing-masing. Namun beberapa dari pengidap agoraphobia berani keluar rumah apabila di-temani oleh orang terpercaya (Hollander \& Simeo, 2008). Agoraphobia pada mulanya dianggap sebagai bagian dari gangguan fobia, namun beberapa bukti terbaru mengungkapkan bahwa agoraphobia merupakan bentuk rumit dari gangguan panik.

Di dalam buku ilustrasi yang akan dirancang, kelima tipe anxiety disorder diatas akan dibahas secara umum. Kelima tipe anxiety disorder akan diwujudkan menjadi sebuah karakter yang akan dijelaskan melalui storytelling tiap karakter tersebut. Harapannya dengan cara tersebut pembaca akan lebih mudah menerima informasi yang dijelaskan dan akan lebih tertarik untuk mencari tahu lebih dalam.

\section{Konsep Perancangan}

Buku ilustrasi ini memperkenalkan sekilas tentang macam-macam anxiety disorder. Minimnyapengetahuan masyarakat mengenai anxiety disorder menyebabkan timbulnya stigma buruk di masyarakat yang dapat menghambat para pengidap untuk mencari pertologan tenaga ahli. Buku ini diharapkan bisa perlahan-lahan mengubah persepsi buruk itu menjadi lebih positif

Isi buku ini terdiri dari infomasi pengenalan masing- masing 5 tipe anxiety disorder dalam wujud karakter. Kelima karakter ini akan menjelaskan macam-macam anxiety disorder melalui narasi dan ilustrasi yang ditampilkan. Karakter akan dirancang adalah karakter fantasi, didesain secara digital, dengan gaya semi- realisme dan warna yang cerah agar persepsi target audiens yang membaca buku ini menganggap anxiety disorder sebagai hal yang dapat diatasi.

Buku Ilustrasi Anxiety Disorder ini ditujukan untuk usia 19-24 tahun. Secara psikologis dan behavioristik, target audiens merupakan orang yang senang mempelajari hal baru, mengikuti tren, dan menyukai hal-hal yang 
berkaitan dengan dunia seni khususnya ilustrasi. Dalam rentang usia ini juga menunjukkan adanya kemandirian dan tanggung jawab terhadap informasi yang diperoleh maupun yang diterima. Target audiens memiliki keinginan membaca untuk menambah wawasan mereka.

Pendekatan yang akan digunakan dalam perancangan ini adalah dengan menggunakan pendekatan psikologi. Pada pendekatan ini, tema akan disajikan berdasarkan informasi seputar anxiety disorder yang didasari oleh teori dan riset di bidang psikologi. Di dalam buku ini nantinya juga akan disajikan beberapa fakta seputar kasus anxiety disorder yang pernah terjadi di dunia.

Format dan ukuran buku adalah:

Ukuran buku : $21 \mathrm{~cm}$ x $21 \mathrm{~cm}$ Format

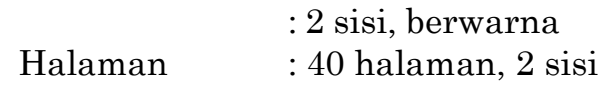

Gaya penulisan naskah yang akan digunakan berupa narasi seputar karakteristik setiap tipe anxiety disorder. Melalui narasi ini nantinya informasi seputaranxiety disorder akan disampaikan. Informasi yangdisajikan berdasarkan hasil riset dan teori pada bidang psikologi. Sudut pandang yang digunakan adalah sudut pandang orang ketiga.

Karakter masing-masing tipe anxiety disorder akan dirancang bersifat fantasi / imajinatif sehingga gaya yang dirasa cocok digunakan adalah gaya semi-realistik. Gaya ilustrasi tersebut dinilai dapat memberi kesan menarik. Pemilihan gestur, bentuk, dan warna yang cerah mampu menghilangkan rasa suram sehingga menarik untuk dilihat. Namun untuk lebih memotivasi pembaca untuk menyimak isi buku tidak terlepas dari komposisi serta unsur story-telling-nya

Visualisasi ilustrasi akan dikerjakan dengan cara digital. Alat yang digunakan antara lain laptop, pen tablet, dan software Adobe Photoshop. Dalam rancangan ini gambar akan dicetak menjadi Buku Ilustrasi.

Berdasarkan jenis buku, yaitu buku ilustrasi, layout yang akan dipilih nantinya cenderung menyeimbangkan antara sisi ilustrasi dengan dengan teksnya. Layout setiap halaman akan menjadi komposisi menarik untuk melihat gambar maupun mempermudah pembacaan. Penjelasan-penjelasan akan mudah dimengerti melalui gambar yang dilengkapi oleh teksnya, sehingga penataan ilustrasi dan tipografinya harus mencapai komposisi yang seimbang dan menarik untuk dibaca.

Warna yang dipilih adalah warna cerah/ saturated, karena warna tersebut sangat berpengaruh dalam mengurangi kesan suram pada gambar. Dengan demikian gaya pewarnaan ini akan sangat mendukungtujuan awal yang ingin mengurangi persepsi buruk/suram terhadap anxiety disorder.

Perancangan ini akan menggunakan tipografi yang memiliki fleksibilitas dan tingkat keterbacaan yang tinggi. Tujuannya adalah agar teks dapat dengan mudah dibaca tanpa membuat mata lelah, sehingga nantinya informasi yang akan disajikan dapat disampaikan dengan mudah dan tidak membosankan.

$\begin{array}{ll}\text { Judul Cover } & \text { : Les Mysteres De Paris } \\ \text { Headline } & \text { : Brandon Grotesque } \\ \text { Body copy } & \text { : Folks-light }\end{array}$

Judul yang akan digunakan pada buku ini adalah "Meeting The Anxiety" yang berarti "Berjumpa dengan Rasa Takut." Judul ini dipilih untuk menggambarkan isi buku secara jelas. Rasa takut yang awalnya merupakan sebuah konsep kini akan diwujudkan secara visual melalui ilustrasi yang disajikan. Harapannya supaya pembaca nanti ingin mengenal lebih dalam tentang anxiety disorder sebagai sebuah kondisi yang dialami manusia.

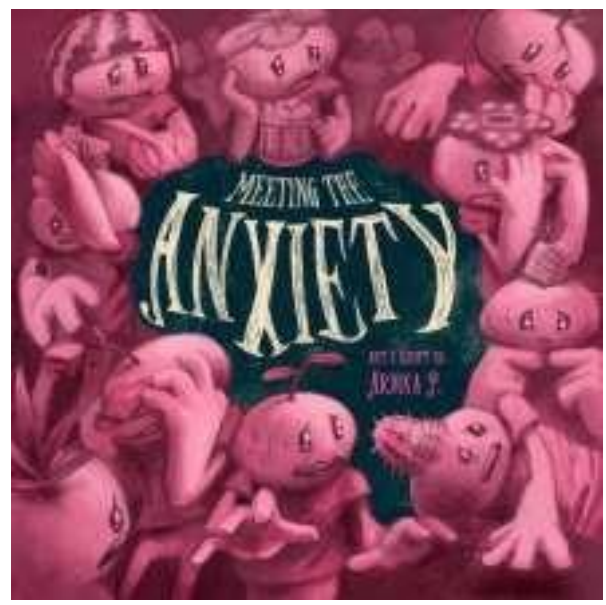

Gambar 1. Sampul depan buku

\section{Pengembangan Desain Deskripsi Karakter Anxiety Disorder}

\section{Generalized anxiety disorder: Kristoffear}

Karakter untuk generalized anxiety disorder dirancang memiliki mulut yang besar. Karakter ini memiliki sikap yang jahil, suka mem- 
buat kecemasan dengan cara menyanyikan lagu tentang ketakutan yang tidak rasional.

Ia mengarang lagu itu dengan mendengar setiap kalimat negatif dari orang lain. Selain itu karakter ini kerap kali menyebarkan ketakutan yang berhubungan terhadap waktu, seperti misal ketidakpastian terhadap masa depan maupun kesalahan yang diperbuat di masa lalu.

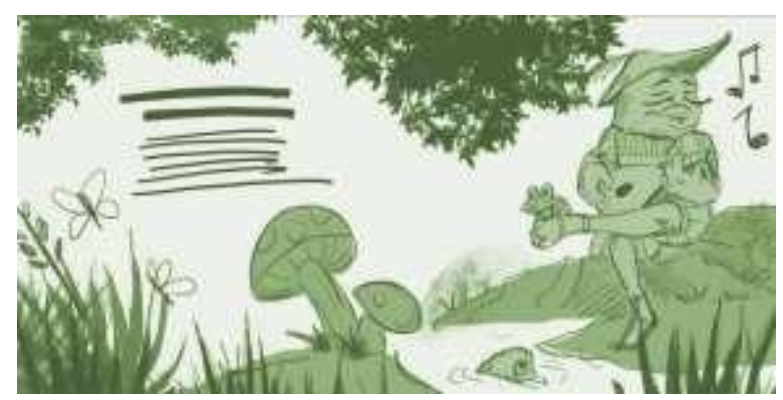

Gambar 2. Thumbnail Karakter Kristoffear

\section{Phobic disorder: Fobius}

Karakter ini digambarkan sebagai penyihir. Mereka menyihir objek maupun situasi tertentu yang awalnya tidak menakutkan menjadi seolah-olah mengerikan dan berbahaya. Para penyihir ini memiliki kecerdasan tinggi sehingga mengerti seluk beluk bagaimana cara membuat semua hal tampak menakutkan. Biasanya mereka menggunakan ingatan yang mengerikan, informasi palsu, maupun memanipulasi mangsanya untuk selalu fokus pada ancaman yang diberikan benda atau situasi tersebut.

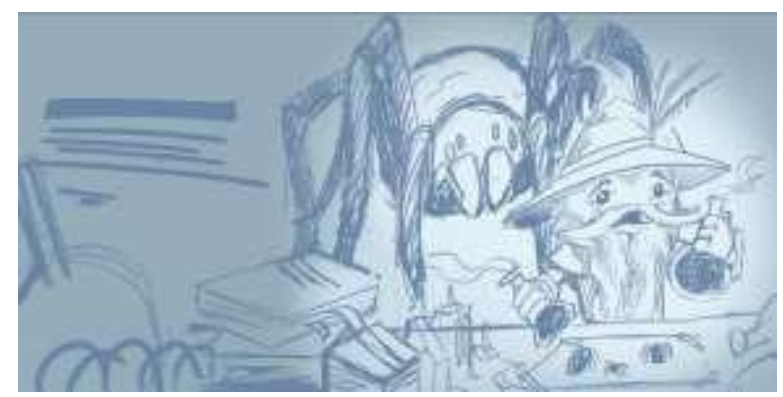

Gambar 3. Thumbnail Karakter Fobius

\section{Panic disorder dan Agoraphobia: Agoilar}

Karakter ini bekerja dengan sembunyi-sembunyi. Ia menyerang secara tidak terduga. Orang yang mengalami kondisi ini seringkali menjadi khawatir dan ketakutan, mereka tidak tahu kapan serangan panik akan terjadi lagi. Bahkan serangan panik dapat terjadi di kerumunan, sehingga membuat orang yang memiliki kon- disi ini semakin takut untuk keluar rumah.

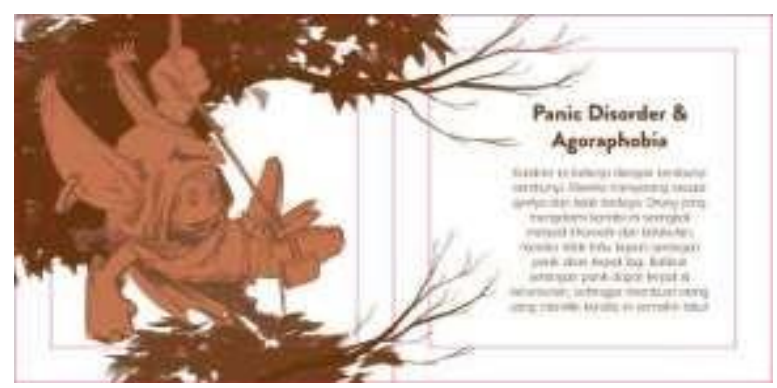

Gambar 4. Thumbnail Karakter Agoilar

\section{OCD: King Osidierre}

OCD bertindak selayaknya raja. Mereka lahir dari obsesi orang-orang yang memiliki kondisi tersebut. Obsesi membuat orang harus menuruti semua perintahnya melalui tindakan impulsif. OCD memiliki sifat seenaknya sendiri, sehingga membuat orang yang mengalami kondisi ini kualahan dan aktivitasnya terganggu.

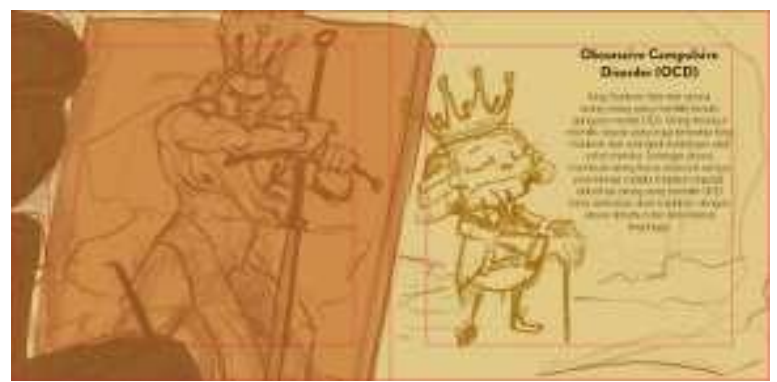

Gambar 5. Thumbnail karakter Osidierre

\section{PTSD: Traugott Maarten}

Orang yang mengalami PTSD merasa seakanakan hidup dengan sejarawan. Karakter PTSD suka mengambil foto, menulis jurnal, dan menata album sehingga orang yang mengalami kondisi ini akan selalu dihantui oleh peristiwa traumatis tersebut. PTSD dengan bangga akan menjelaskan peristiwa traumatis yang ia rekam secara rinci dan jelas. Bahkansangat jelas sampai terasa seperti sebuah flashback yang nyata. PTSD tinggal di dalam musium imajinatif dalam kepala orang yang mengalami PTSD.

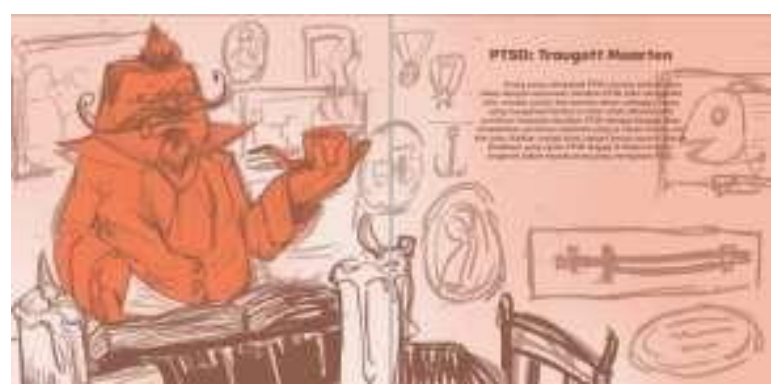

Gambar 6. Thumbnail karakter Traugott 


\section{Ego}

Ego merupakan perwakilan posisi orang yang mengalami anxiety disorder. Karakter ini berwujudseperti manusia, dengan bunga atau tanaman di atas kepala mereka. Tanaman tersebut melambangkan wujud psikis (buah pikiran) yang dimiliki manusia.

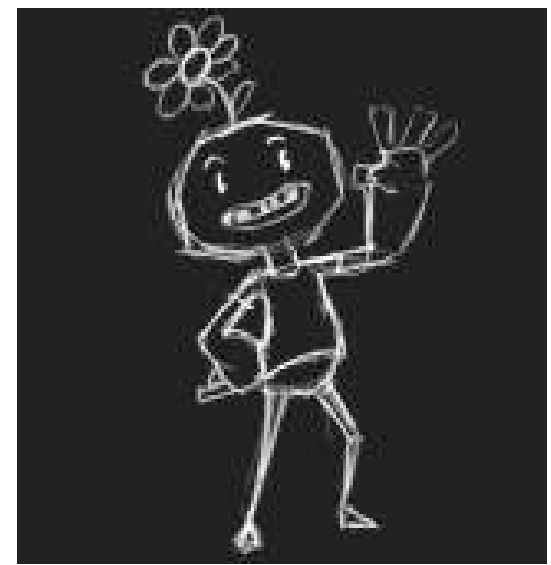

Gambar 7. Thumbnail karakter Ego
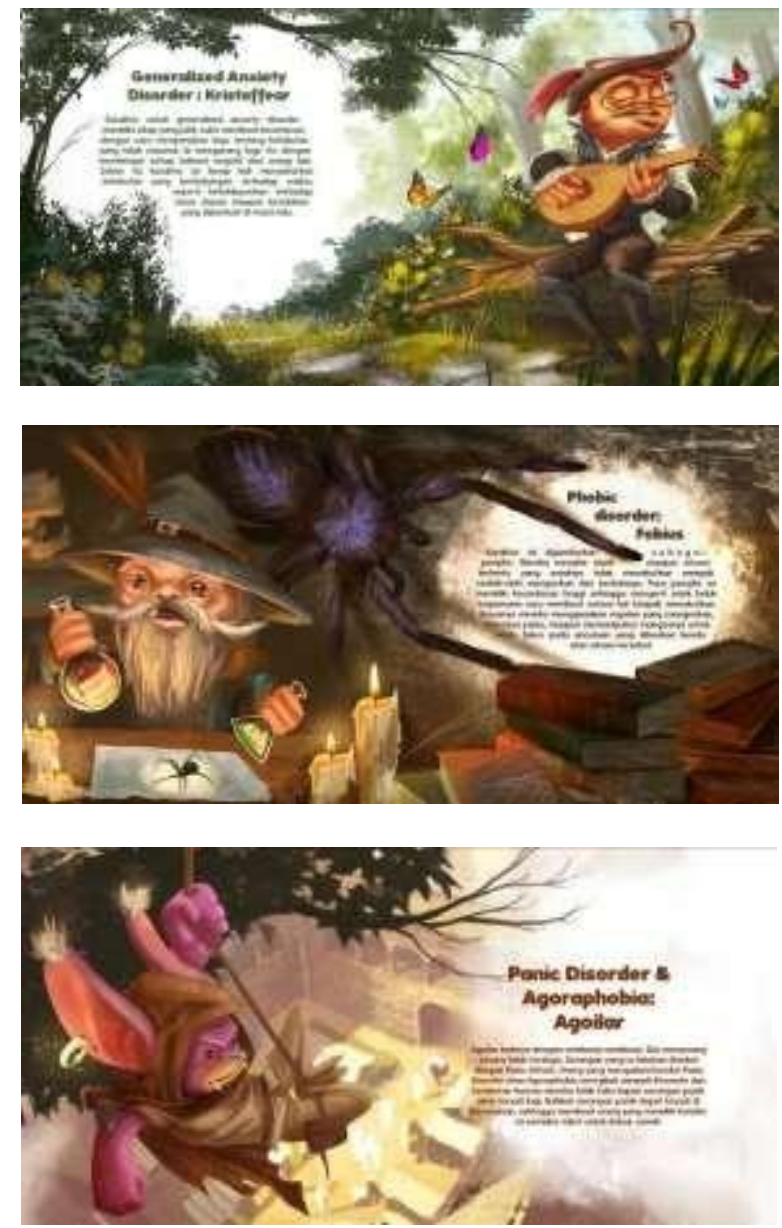

(a)
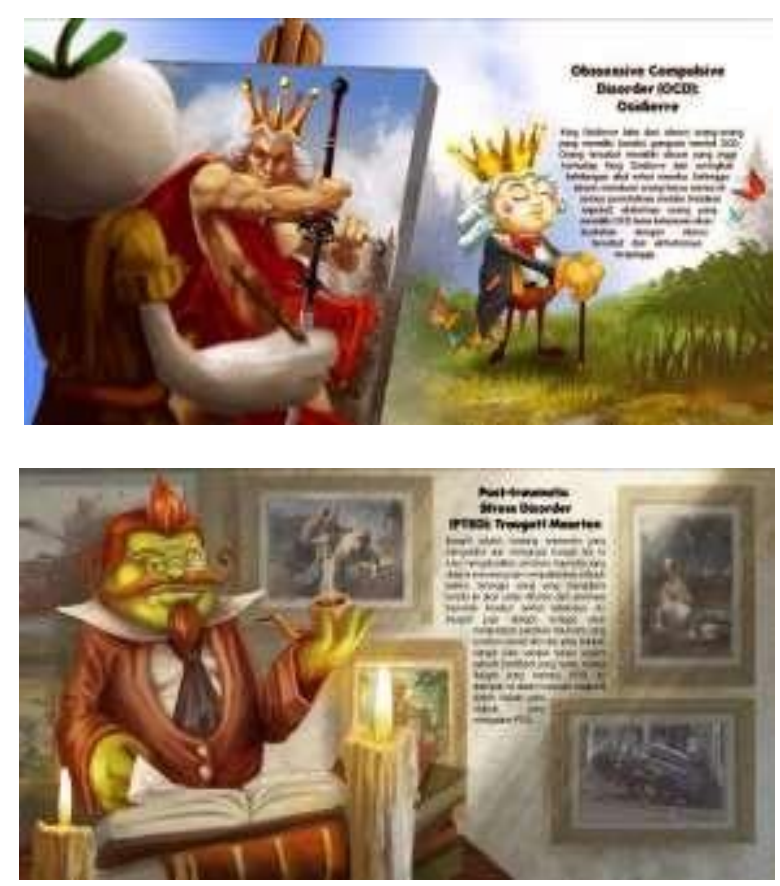

(b)

Gambar 8. (a), (b) Hasil Final Karakter Anxiety Disorder
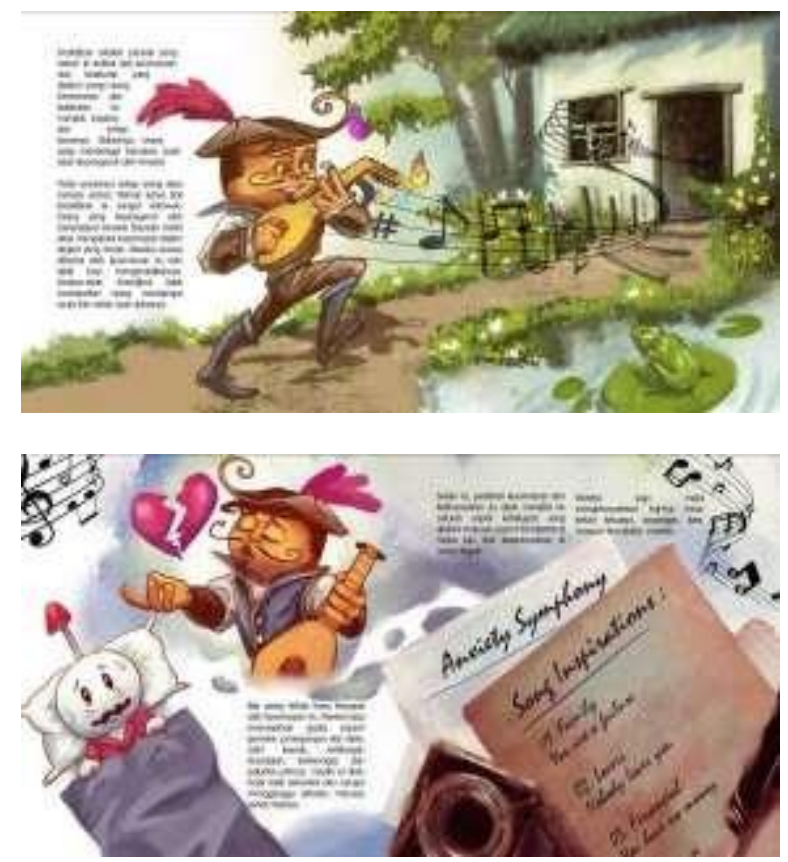

Gambar 9. Layout Isi Konten Buku Ilustrasi

Di dalam buku ini juga akan disediakan fakta unik dengan desain halaman interaktif. Hal ini ditujukan untuk menambah kesan immersive ketika membacabuku ini. Harapannya pembaca tidak mudah bosanketika membaca isi buku ini. 


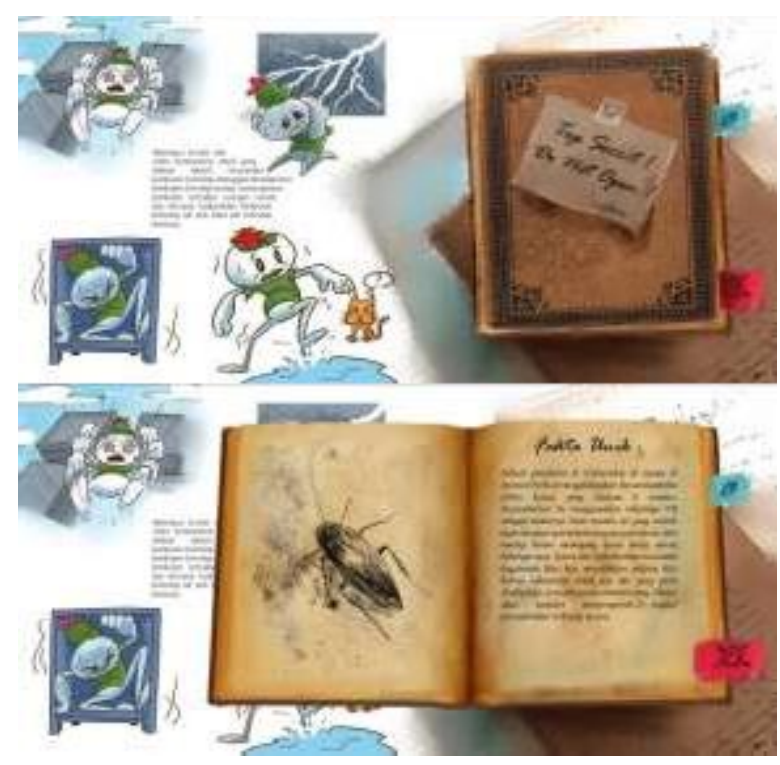

Gambar 10. Contoh Halaman Fakta Unik yang Dirancang Interaktif

Buku ini tidak dapat digunakan sebagai alat untuk mendiagnosa diri. Artinya pembaca tetap harus menghubungi tenaga medis untuk mendapat diagnosa bila dirasa perlu. Buku ini juga mengarahkan dan mengedukasi pembaca agar dapat memahami soal proses pengobatan dan siapa saja tenaga medis yang dapat melakukan proses pengobatan tersebut.
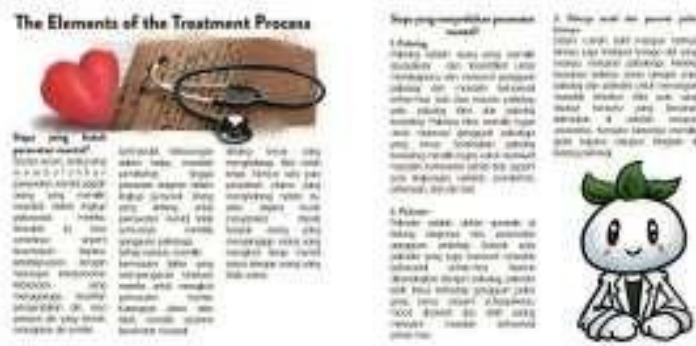

Gambar 11. Halaman yang menerangkan elemenelemen proses pengobatan
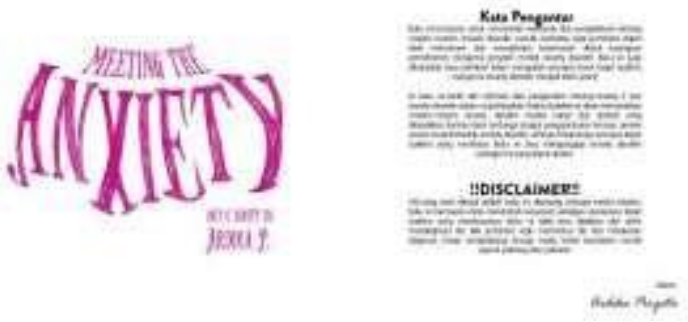

Gambar 12. Disclaimer bahwa buku ini tidak dapat digunakan sebagai alat untuk mendiagnosa diri

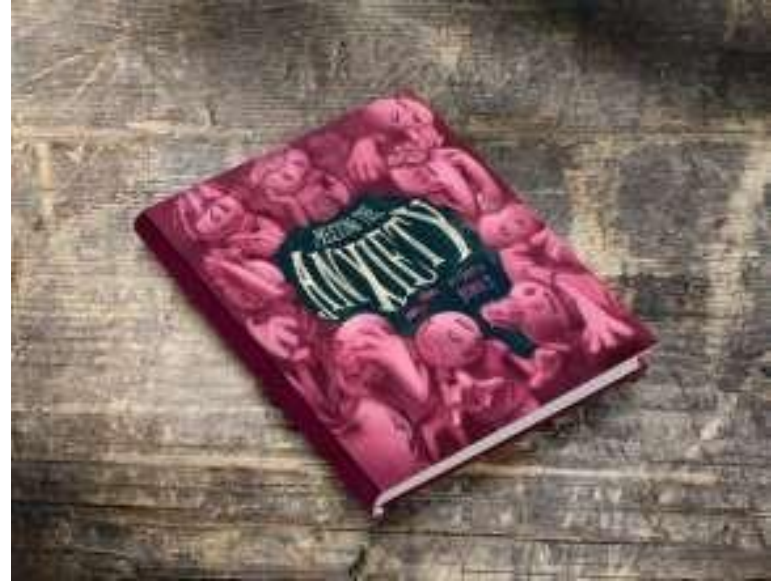

Gambar 13. Tampilan Buku Ilustrasi

\section{Simpulan}

Buku ilustrasi ini dapat menjawab masalah kurangnya wawasan dan pengetahuan tentang macam-macam anxiety disorder yang ditujukan untuk usia 19-24 tahun. Media ilustrasi sendiri terbukti telah menjadi sumber visualisasi ide dan pikiran manusia sepanjang waktu. Fungsi dari ilustrasi dalam buku ini juga dinilai dapat mengubah kesan suram yang ada pada anxiety disorder, sehingga pada akhirnya target audiens dapat lebih memahami dan mengurangiadanya stigma buruk akibat kurangnya pemahaman mengenai penyakit mental anxiety disorder.

\section{Daftar Pustaka}

Aleixo, P., \& Baillon, M. (2008). Biological Psychology an Illustrated Survival Guide. John Wiley \& Sons Ltd.

Artikelsiana.com. (2017). Pengertian Ilustrasi, Fungsi, Tujuan, Jenis \& Contoh Ilustrasi. Retrieved from www.artikelsiana.com/ 2017/09/pengertian-ilustrasi-fungsitujuan.html

BBC News Indonesia. (2019, Oktober 10). Hari Kesehatan Jiwa Sedunia: 'Saya merasa benar-benar sendiri hingga sempat ingin bunuh diri'. Retrieved from www.bbc.com/ indonesia/indonesia-49987127

Essays UK. (2018, November). The Effect of Colours: Emotion and Symbolism of Colour. Retrieved from www.ukessays.com/essays/ film-studies/how-colour-affects-mood-andemotion-film-studies- essay.php?vref=1

Goleman, D. (1995). Emotional Intelligence. BantamBooks. 
Kompas. (2019, Oktober 15). Berkaca dari Kasus Sulli Mengapa Banyak Tokoh Terkenal Alami Depresi? Retrieved from Kompas.com: www.kompas.com/tren/read/2019/10/15/11105 2265/berkaca-dari-kasus-sulli-mengapabanyak-tokoh-terkenal-alami-depresi? page $=$ all

KQED Inc. US. (2017, March). These Fighting Fruit Flies Are Superheroes of Brain Science. Retrieved from KQED Science: www.kqed.org/ science/1494923/these-fighting-fruit-fliesare-superheroes-of-brain-science

Maramis, W. F., \& Maramis, A. A. (2010). Catatan Ilmu Kedokteran Jiwa (Edisi 2). Airlangga University Press.

Rohidi, \& Tjetjep, R. (1984). Lintasan Peristiwa dan Tokoh Seni Rupa Indonesia Baru. Semarang: IKIP Semarang Press.
Soedarso. (1990). Tinjauan Seni Sebuah Pengantar Untuk Apresiasi Seni. Yogyakarta: Saku Dayar Sana.

Triadi, D., \& Sugiarto, A. (2014). Color Vision. Kompas.

Tribun News. (2020, January 21). Siswi SMP yang Lompat dari Lantai 4 Sekolah Ternyata Pernah Curhat Soal ini ke Kakak. Retrieved January 30,2020, from Tribun-Timur.com: makassar.tribunnews.com/ 2020/01/21/siswi-smp-yang-lompat-darilantai-4-sekolah-ternyata-pernah-curhatsoal-ini-ke-kakak

Weiten, W. (2013). Psychology Themes and Variations 9th edition. Wadsworth: Cengage Learning.

Witabora, J. (2012, Oktober). Peran dan Perkembangan Ilustrasi. Humaniora. 3(2), 659667 